\title{
Phenotypic Detection and Genotypic Characterization of Metallo-Beta- Lactamases in Gram Negative Bacilli isolated from Mansoura University Hospital in Egypt
}

\author{
Maysaa El-Sayed Zaki, Mervat Mashaly* and Reham El Agamy
}

\author{
Clinical Pathology Department, Faculty of Medicine, Mansoura University-Egypt \\ *Corresponding author
}

\section{A B S T R A C T}

\begin{tabular}{l} 
K e y w o r d s \\
$\begin{array}{l}\text { Double-disk } \\
\text { synergy test, Gram } \\
\text { negative bacilli, } \\
\text { Metallo-ßeta- } \\
\text { lactamases, PCR. }\end{array}$ \\
\hline Article Info \\
$\begin{array}{l}\text { Accepted: } \\
\text { 24 January } 2017 \\
\text { Available Online: } \\
\text { 10 February } 2017\end{array}$ \\
\hline
\end{tabular}

Metallo- $\beta$-lactamases (M $\beta$ Ls) production in gram negative bacilli is an emerging health problem worldwide. We aimed to determine the occurrence of M $\beta$ Ls among gram negative bacilli (GNB) by phenotypic and genotypic methods in Mansoura University hospital, Egypt. We conducted a prospective study on 107 GNB isolates recovered from different clinical specimens collected from different patients. Species identification and antibiotic susceptibility profile was determined by MicroScan Wa1kAway system. GNB which showed resistance to imipenem and/or meropenem were screened for MBL production by double-disk synergy test (DDST). Phenotypically detected MBLs isolates were further studied for the presence of three genes; IMP, GIM and VIM by multiplex PCR. Out of 107 GNB isolates, $62(57.9 \%)$ strains showed resistance to imipenem and/or meropenem. DDST detected MBLs in $46.8 \%$ of carbapenem resistant isolates.65.5\% of phenotypically detected M $\beta \mathrm{Ls}$ isolates were carrying genes for M $\beta \mathrm{Ls}$ production. IMP was the most frequent detected gene (36.8\%) followed by VIM, and GIM genes (31.6\% for each). M $\beta L$ s production were more frequent in E.coli, Pseudomonas species, Acintobacter species (26.3\% for each) followed by Klebsiella species (15.8\%) and Moraxella species (5.3\%). Our findings showed production of M $\beta$ Ls in a considerable number of GNB which is alarming and need continuous surveillance to detect such resistant strains. DDST is simple method and could be routinely applied for early detection ofthis resistance to establish the proper antibiotic therapy and infection control measures to combat their spread. Future studies are needed for extensive molecular characterization of M $\beta$ Lsamong GNB in our locality.

\section{Introduction}

Worldwide antimicrobial resistance is an increasing problem which occur more in those hospitals where antibiotic is used frequently and the patients are in critical condition (Wadekar et al., 2013). $\beta$-lactamases are the most important mechanism responsible for antibiotic resistance in gram negative bacilli (GNB) because of their wide range of substrate specificity and their ability to hydrolyze many of $\beta$-lactams antibiotics (Fam et al., 2006).

Based on conserved and distinguishing amino acid motifs, $\beta$-lactamases enzymes are classified into four molecular classes. A, C, and $\mathrm{D}$ classes of $\beta$-lactamases contain enzymes that hydrolyze their substrates by formation of an acyl-enzyme through an 
active site serine, but class B $\beta$-lactamases calledmetallo-beta-lactamases (MßLs) as it needs zinc ion for its activity (Bush and Jacoby, 2010).

M $\beta$ Ls producing bacteria have the ability to hydrolyze wide spectra of beta-lactam containing antibiotics including penicillins, cephalosporins, cephamycins and carbapenems, but cannot hydrolyze monobactam as aztreonam. Also, M $\beta$ Lscatalytic activities are inhibited by metal-chelating agents such as ethylenediaminetetraacetic acid (EDTA) and not inactivated by inhibitors of $\beta$-lactamase such as tazobactam, clavulanate, and sulbactam (Bebrone, 2007).

Five MßLstypes, on the basis of amino acid sequence homology, have been identified; imipenemase (IMP), Verona integron-encoded metallo- $\beta$-lactamase (VIM), German imipenemase (GIM), Sao Paulo metallo- $\beta$-lactamase (SPM), and Seoul imipenemase (SIM) types (Lee and Lee, 2006).

Genes for acquired M $\beta$ Ls are carried on highly mobile which facilitate its horizontal transfer to other pathogens in the hospital, permitting easy and unnoticed dissemination within hospital. Therefore, presence of M $\beta$ Ls producing bacteria in a hospital is considered a therapeutic problem as well as a serious concern for infection control management (Pandya et al., 2016). So, the rapid detection of beta lactamase producing bacteria is important not only to decrease mortality rates for patients but also to avoid spread of such strains in the hospital environment (Wadekar et al., 2013).

Several phenotypic methods have been described for detection of M $\beta$ Lsamong clinical isolates as double disc synergy test and combined disk using metal chelating agent such as EDTA and thiol compounds, inhibitors of $\mathrm{M} \beta \mathrm{Ls}$-activity, in combination with $\beta$-lactams (Fam et al., 2006). Based on analysis of genetic materials that is unique and variable for each organism, several molecular methods as PCR are currently used for analysis of genetic contex and detection of different types of M $\beta$ Ls (Pitout et al., 2005). However, currently, there are no recommendations available from the CLSI (Clinical and Laboratory Standards Institute) or elsewhere for the detection of $\mathrm{M} \beta \mathrm{Ls}$ producing organisms. Therefore, we aimed to detect and characterize $\mathrm{M} \beta \mathrm{L}$ producing GNB in Mansoura University Hospital and to evaluate Imipenem-EDTA double-disk synergy test (DDST) as phenotypic screening method for detection of M $\beta$ Ls.

\section{Materials and Methods}

This prospective study was carried out through the period from March 2014 till March 2015 with an approval from the Local Ethical Committee of Faculty of MedicineMansoura University (MFM- Institutional Research Board). A total of 107 gram negative bacilli (GNB) isolates were obtained from random clinical samples of patients admitted to Mansoura University Hospital. These samples comprised of blood, urine, stool, wound swab, sputum, bronchoalveolar lavage (BAL), and CSF. Collection of samples were done under strict aseptic precautions according to standard protocols and processed at once (Collee et al., 1996).

\section{Isolation of gram negative bacilli}

All clinical samples were cultured directly on MacConkey agar. Blood samples were inoculated into BACTEC aerobes Plus ${ }^{\mathrm{TM}} / \mathrm{F}$ culture bottles (Becton Dickinson Diagnostic systems, USA) then incubated in the BACTEC fluorescent series instrument for periodic reading. Subcultures on MacConkey 
agar were done for all BACTEC culture bottles with positive growth. GNB were identified by Gram staining of the organisms grown on MacConkey agar.

\section{Identification and susceptibility testing of GNB isolates}

GNB isolates were further identified up to the species level by Microscan Gram Negative Breakpoint Combo panels Type 20 on The Micro Scan Wa1kAway diagnostic microbiology system (Semens Health Car Dagnostics, formerly Dade Behreng, USA) according to the manufacturer's manual. In brief, inocula were prepared using the Prompt ${ }^{\mathrm{TM}}$ Inoculation System for preparation of standardized inocula. Panel Rehydration and inoculation were performed using the RENOK system with Inoculators -D (B10134). A final well concentration of 3-7 X $10^{5}$ $\mathrm{CFU} / \mathrm{ml}$ was achieved. Results were recorded on MicroScan instrumentation screen.

\section{Phenotypic detection of M $\mathrm{BLs}$ production byImipenem-EDTA double-disk synergy test}

A total of $62 \mathrm{GNB}$ isolates with antibiotics resistance towards imipenem and/or meropenem were investigated for $\mathrm{M} \beta \mathrm{Ls}$ production by double-disk synergy test (DDST) according to Lee et al., 2003. Briefly, suspension of an overnight culture of the tested strain was adjusted the turbidity of 0.5 McFarland, then used to swab MullerHington agar surface. After drying, an imipenem disc $(10 \mu \mathrm{g})$ was placed at a distance of $20 \mathrm{~mm}$ from the center of a blank sterile filter paper. Thereafter, $10 \mu \mathrm{l}$ of $0.1 \mathrm{M}$ EDTA ( $\mathrm{pH} \mathrm{8)}$ was applied to the blank disc. The plate was incubated at $37^{\circ} \mathrm{C}$, increase of the inhibition zone in the area between the EDTA disk and imipenem disk as compared to inhibition zone on the far side of imipenem disk was interpreted as a positive for M $\beta L$ s.

\section{Molecular detection of genes encoding MßLs by Multiplex PCR}

Detection of the most common genes (IMP, $V I M$, and GIM) responsible for $\mathrm{M} \beta \mathrm{L}$ activity was performed by Multiplex PCR for the 29 phenotypically detected M $\beta \mathrm{Ls}$ isolates according to Ellington et al., (2007).

\section{DNA extraction}

DNA of the different isolates was extracted by the DNA extraction kit (QIAGEN; GmbH, Hilden, Germany) as per manufacturer's instructions.

\section{DNA amplification}

Multiplex PCR for amplification and detection of the studied $3 M B L s$ genes was done in a single reaction. 5ul of the DNA extract was added to $25 \mathrm{ul}$ of PCR master mix, $1 \mathrm{ul}$ of each forward primer, $1 \mathrm{ul}$ of each reverse primer and then completed with nuclease free water to reach a total volume of 50ul. The cycling condition used for amplification was as follows: initial denaturation at $94^{\circ} \mathrm{C}$ for 5mins, 36 cycles of denaturation at $94^{\circ} \mathrm{C}$ for $30 \mathrm{~s}$, annealing at $52^{\circ} \mathrm{C}$ for $40 \mathrm{~s}$ and extension at $72^{\circ} \mathrm{C}$ for $50 \mathrm{~s}$, followed by a single cycle for final extension at $72^{\circ} \mathrm{C}$ for 5 mins. The produced amplicons were separated on agarose gel $(2 \%)$ then the particular bands were visualized using UV transilluminator. Primers sequences and the amplification products size are summarized in table 1.

\section{Statistical analysis}

Data were analyzed using SPSS statistical package programme (version 16, SPSS, Chicago, IL). Normal distribution of variables was tested with the Kolmogorov-Smirnov test. The results were expressed as percentages for categorical variables, $\mathrm{p}$ value 
of $\leq 0.05$ was considered statistically significant.

\section{Results and Discussion}

A total of 107 Gram Negative Bacilli isolates (GNB) were recovered from different clinical specimens. The largest proportion of specimens was blood (28.9\%), BAL (24.2\%), wound swabs (22.4\%), followed by stool samples (6.5\%), urine samples $(6.5 \%)$ and peritoneal fluid (3.7\%). Species of the 107 studied GNB isolates are summarized in table (2)

The isolated GNB were most resistant for trimethoprim (75.7\%), followed by piperacillin and cefepime $(72.9 \%)$, tetracyclin (69.1\%), cefuroxime and ampicillin $(63.5 \%$ for each), tobramycin and ampicillin/ sulbactam (61.6\%), and cefazolin (57.9\%). Imipenem and meropenem resistance (as a screening for carbapenem resistance) was detected in $43(40.2 \%)$ and $30(28 \%)$ of isolates respectively, table (3).

Double disc synergy test detected M $\beta$ Ls in 29 (46.8\%) of $62 \mathrm{GNB}$ isolates with resistance to imipenem and/or meropenem. Multiplex PCR revealed that out of these 29 phenotypically detected M $\beta$ Ls, the three genes (IMP, VIM and $G I M)$ responsible for MBL activity were detected only in $19(65.5 \%)$ isolates, table (4).

The most common gene responsible for M $\beta \mathrm{Ls}$ among GNB as identified by multiplex PCR was IMP; 7/19(36.8\%) followed by VIM, and GIM genes; 6/19 (31.6\% for each), figure (1). Genes for M $\beta$ Lswere detected more frequently among E. coli, Pseudomonas and Acinatobacter species (26.3\% for each) followed by Klebsiella species (15.8\%) and Moraxella species (5.3\%) (Table 5).

Gram-negative bacilli (GNB) are one of the most important reasons of sever hospital acquired and community-onset bacterial infections in humans (Pitout, 2008). Emerging antimicrobial resistance is a growing problem in many pathogens throughout the globe despite the discovery of newer antibiotics (Shlaes et al., 1997; Pfaller et al., 1998). Several parts of the world have been reported M $\beta$ Ls producing GNB which is the most widespread and clinically significant mechanism of carbapenem resistance (Rasheed et al., 2013). Therefore, we tried to detect the presence of M $\beta \mathrm{L}$ producing GNB phenotypically and genotypically in our Mansoura University Hospital.

We investigated 107 isolates of GNB recovered most frequently from blood, BAL, wound and stool samples. Frequent isolation of GNB from nosocomial infections could be linked to many risk factors such as long hospitalization more than 8 days, previous use of antibiotic, trauma and mechanical ventilation which may contribute to the mortality (Kumar et al., 2012 ).

Among these 107 GNB isolates, the most common species identified were E-coli, Pseudomonas, Klebsiella, followed by Acinobacter, Moraxella, Citrobacter. The least identified species were Enterobacter, Salmonella, Kluyvera, Shigella, Aeromonas, Bordetella, Edwardsiella, Plesiomonas and Proteus. This distribution of GNB coincided with a study carried out in our locality, Zagazig University Hospitals, Egypt which reported Escherichia coli, Klebsiella pneumoniae and $P$. aeruginosaas the commonest species among GNB (Mohammed et al., 2016).

Pattern of resistance among nosocomial bacterial organisms may differ widely from country to country at any time and even within the same country over time (Prashanth and Badrinath, 2004). In the Middle East, the occurrence of carbapenem-resistant GNB is alarmingly increased. In our study, 43 $(40.2 \%)$ and $30(28 \%)$ of the isolates were 
resistant to imipenem and meropenem, respectively. Similarly, Mohammed et al., (2016) and Mohamed and Raafat (2011) showed a high level of imipenem resistance among GNB (50.8\% and 52.2\% respectively). This increase in prevalence of carbapenemresistant GNB could be due to extensive use of carbapenems which has likely generated a selective antibiotic pressure (Mohammed et al., 2016). Prevalence of M $\beta$ Ls among the carbapenem resistant isolates across the world as shown in various studies varied from $44.5 \%$ to $96.3 \%$ (Kaleem et al., 2016; Pandya et al., 2011; Chaudhary et al., 2008). We found that out of the 62 imipenem and or meropenem resistant isolates screened for M $\beta$ Ls production, only 29 (46.8\%) were MBLs producers.

Table.1 Sequence of primers used in amplification of metallobeta-lactamases genes and their amplification products (9)

\begin{tabular}{|c|c|c|}
\hline Gene & Primer sequence & Amplicon size \\
\hline \multirow{2}{*}{$I M P$} & F (5'-GGA ATA GAG TGG CTT AAY TCT C-3') & \multirow{2}{*}{$188 \mathrm{bp}$} \\
\hline & R (5'-CCA AAC YAC TAS GTT ATC T-3') & \\
\hline \multirow{2}{*}{ VIM } & F (5'-GAT GGT GTT TGG TCG CAT A-3') & \multirow{2}{*}{$390 \mathrm{bp}$} \\
\hline & R (5'-CGA ATG CGC AGC ACC AG-3') & \\
\hline \multirow{2}{*}{ GIM } & F (5'-TCG ACA CAC CTT GGT CTG AA-3') & \multirow{2}{*}{$477 \mathrm{bp}$} \\
\hline & R (5'-AAC TTC CAA CTT TGC CAT GC-3') & \\
\hline
\end{tabular}

Table. 2 Bacterial species of the studied isolates

\begin{tabular}{lcc}
\hline Bacterial species & Number & \% \\
\hline E.coli & 48 & 44.9 \\
Pseudomonas & 13 & 12.1 \\
Klebsiella & 10 & 9.3 \\
Acinobacter & 8 & 7.4 \\
Moraxella & 6 & 5.6 \\
Citrobacter & 5 & 4.6 \\
Enterobacter & 4 & 3.7 \\
Salmonella & 4 & 3.7 \\
Kluyvera & 2 & 1.8 \\
Shigella & 2 & 1.8 \\
Aeromonas & 1 & 0.9 \\
Bordetella & 1 & 0.9 \\
Edwardsiella & 1 & 0.9 \\
Plesiomonas & 1 & 0.9 \\
Proteus & 1 & 0.9 \\
Total bacterial & $\mathbf{1 0 7}$ & $\mathbf{1 0 0}$ \\
isolates & & \\
\hline
\end{tabular}


Table.3 Antibiotic profile of isolated bacterial species

\begin{tabular}{lccc}
\hline ANTIBIOTIC & $\begin{array}{c}\text { Resistant } \\
\text { No }(\boldsymbol{\%})\end{array}$ & $\begin{array}{c}\text { Intermediate No } \\
(\boldsymbol{\%})\end{array}$ & $\begin{array}{c}\text { Sensitive } \\
\text { No }(\boldsymbol{\%})\end{array}$ \\
\hline Trimethoprim & $81(75.7)$ & $9(8.4)$ & $17(15.9)$ \\
Piperacillin & $78(72.9)$ & $7(6.5)$ & $22(20.6)$ \\
Cefepime & $78(72.9)$ & $2(1.9)$ & $27(25.2)$ \\
Tetracycline & $74(69.1)$ & $8(7.5)$ & $25(23.4)$ \\
Cefuroxime & $68(63.5)$ & $4(3.8)$ & $35(32.7)$ \\
Ampicillin & $68(63.5)$ & $3(2.9)$ & $36(33.6)$ \\
Tobramycin & $66(61.7)$ & $14(13.1)$ & $27(25.2)$ \\
Ampicillin / sulbactam & $66(61.7)$ & $6(5.6)$ & $35(32.7)$ \\
Cefazolin & $62(57.9)$ & $2(1.9)$ & $43(40.2)$ \\
Ceftazidime & $61(57)$ & $6(5.6)$ & $40(37.4)$ \\
Cefoxitin & $57(53.2)$ & $5(4.7)$ & $45(42.1)$ \\
Levofloxacin & $55(51.4)$ & $10(9.3)$ & $42(39.3)$ \\
Piperazine & $55(51.4)$ & $9(8.4)$ & $43(40.2)$ \\
Ceftriaxone & $54(50-.4)$ & $11(10.3)$ & $42(39.3)$ \\
Amp. / clavulanic acid & $50(46.7)$ & $6(5.6)$ & $51(47.7)$ \\
Ciprofloxacin & $48(44.8)$ & $4(3.8)$ & $55(51.4)$ \\
Gentamicin & $48(44.8)$ & $2(1.9)$ & $57(53.3)$ \\
Imipenem & $43(40.2)$ & $2(1.9)$ & $62(57.9)$ \\
Amikacin & $41(38.3)$ & $6(5.6)$ & $60(56.1)$ \\
Meropenem & $30(28)$ & $8(7.5)$ & $69(64.5)$ \\
Tigecycline & $7(6.5)$ & $4(3.7)$ & $96(89.8)$ \\
Cefotaxime & $81(75.7)$ & $12(11.2)$ & $14(13.1)$ \\
Aztreonam & $8(7.4)$ & $4(3.8)$ & $95(88.8)$ \\
& & & \\
\hline
\end{tabular}

Table.4 Detection of metallobeta-lactamases among gram negative bacilli by phenotypic and genotypic methods

\begin{tabular}{ccc}
\hline & No & \% \\
\hline MBLs-GNB by synergy test & $29 / 62$ & 46.8 \\
MBLs - GNB by multiplex PCR & $19 / 29$ & $65.5 \%$ \\
\hline
\end{tabular}

GNB: gram negative bacilli

Table.5 Bacterial species positive for metallobeta-lactamases by double disc EDTA testand Multiplex PCR

\begin{tabular}{lcc}
\hline \multicolumn{1}{c}{ Bacterial Species } & $\begin{array}{c}\text { double disc EDTA test } \\
\text { No }(\%)\end{array}$ & $\begin{array}{c}\text { Multiplex PCR } \\
\text { No }(\%)\end{array}$ \\
\hline E.coli species & $7(24.1)$ & $5(26.3)$ \\
Pseudomonas species & $7(24.1)$ & $5(26.3)$ \\
Klebsiella species & $5(17.2)$ & $3(15.8)$ \\
Acinobacter species & $7(24.1)$ & $5(26.3)$ \\
Moraxella species & $3(10.3)$ & $1(5.3)$ \\
Total bacterial isolates & $29(100)$ & $19(100)$ \\
\hline
\end{tabular}


Figure.1 Frequency of genotypes among metallobeta-lactamases producing Gram negative bacilli by multiplex PCR

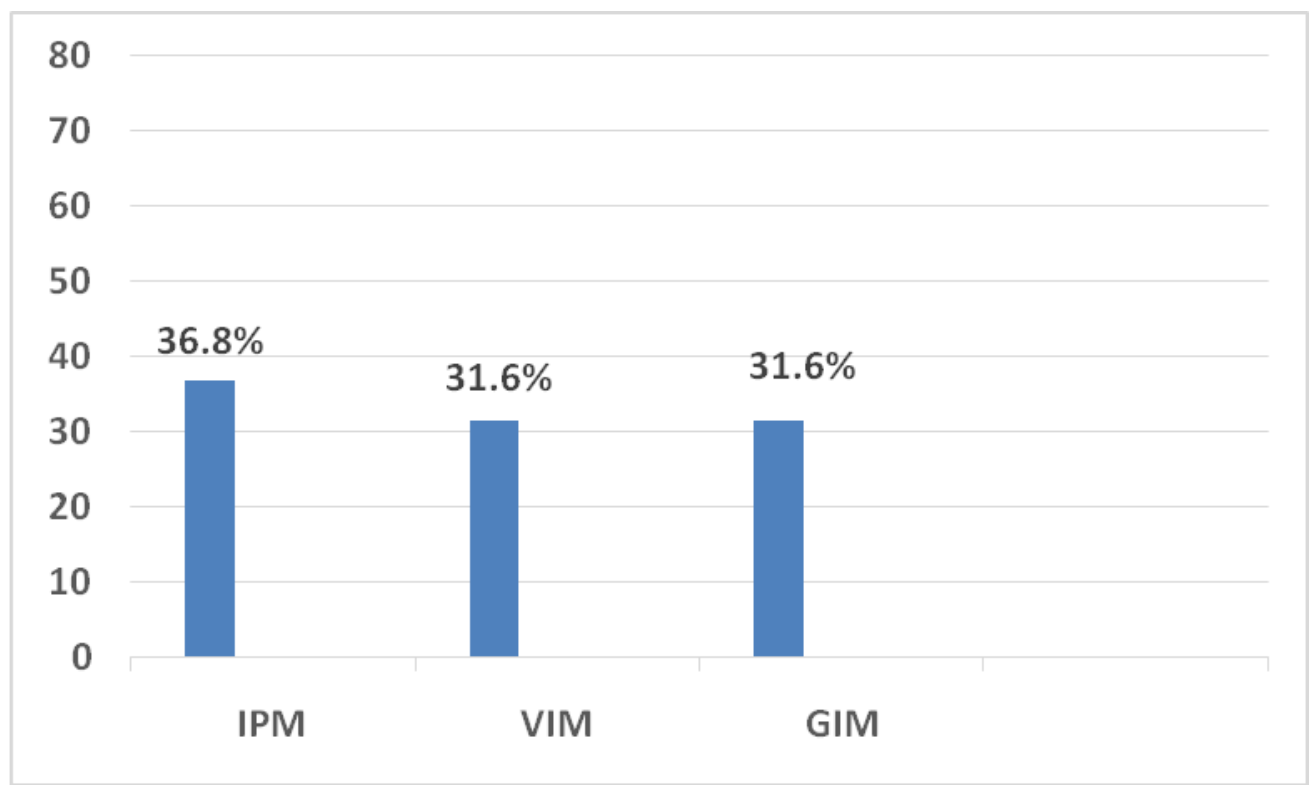

Carbapenems resistance detected in the remaining 33 MBLs non producers could be caused by other mechanisms such as diminished permeability of outer membrane, increased efflux systems or change of penicillin binding proteins (Tellis et al., 2013).

Prevalence rate of M $\beta$ Ls (as detected phenotypically by DDST) in the present study was higher than a previous study in our locality which detected M $\beta$ Ls only in $20 \%$ of their studied GNB (El-Kazzaz and Abou Elkhier, 2015). Difference in M $\beta L$ s prevalence could be attributed to many reasons as different age groups, different clinical samples, and different methods for $\mathrm{M} \beta \mathrm{Ls}$ detection or use of different species in the studies (Pandya et al., 2016). It is known that M $\beta$ Ls are more frequent among Pseudomonas aeruginosa species (Lister et al., 2009).

In the present study, Only $19(65.5 \%)$ of the 29 phenotypically detected M $\beta$ Ls producing isolates was found to be positive for the studied M $\beta$ Ls genes. Phenotypically detected M $\beta$ Ls with no genotypic mark of MBLs production might harbor other M $\beta$ Ls genes, such as OXA-type, that were not investigated in this study. Another probable explanation mightbe the susceptibility of some bacterial strains to EDTA, which could affect permeability of bacterial membrane, resulting in false positive results of phenotypic tests used for the M $\beta L s$ detection (Karthika et al., 2009; Aktas and Kayacan, 2008). In general, phenotypic method, especially DDST is reported to be sensitive for detection of $\mathrm{M} \beta \mathrm{Ls}$ due to wide genetic varieties among gram negative bacilli isolated from clinical samples (Omair et al., 2012).

Percentage of genes responsible for $M \beta L s$ among our studied GNB by multiplex PCR, was $36.8 \%$ for $I M P$ and $31.6 \%$ for each of VIM, and GIM genes. Also Anoar et al (2014) reported that $I M P$ is the most frequently found $M \beta L$ s gene among their studied isolates and it recorded a higher percentage of detection than VIM genes. On contrary to our findings, Chakraborty et al., (2011), found that most of the studied strains harbor VIM genes and not detected IMP genes in any of 
studied strains. In the beginning, these M $\beta$ Ls were commonly detected in Klebsiella species and E. coli (Mathur et al., 2002), but now they are produced by all Enterobacteriaceae and other Gram negative bacteria (Kumar et al., 2006).

Our study detected M $\beta$ Ls more frequently among E. coli, Pseudomonas species, Acintobacter species, followed by Klebsiella species and Moraxella species. Also, Naveenkumar et al., (2014) found that prevalence of $\mathrm{M} \beta \mathrm{Ls}$ production, is highest in Pseudomonas (50\%), E. coli (34\%) and Acinetobacter (16\%) but not in other gram negative bacilli. In the same context, there are frequent reports of $\mathrm{M} \beta \mathrm{Ls}$ production in Pseudomonas aeruginosa and Acinetobacter species from different areas of the world (Nordmann and Poirel, 2002; Noyal et al., 2009; Mishra et al., 2012; Altun et al., 2013). In conclusion, there is a considerable high prevalence of carbapenem resistance among our clinical GNB isolates. Imipenem-EDTA double-disk synergy test identified $46.8 \%$ of this carbapenem resistance as M $\beta \mathrm{Ls}$ producers. PCR based detection methods are expensive, need experts and identified only $65.5 \%$ of these phenotypically detected M $\beta$ Ls.

The most frequent M $\beta$ Ls genes detected in our isolates were IMP followed by $V I M \& G I M$. Therefore, all GNB isolates with resistant to cabapenem should be screened for M $\beta$ Ls production by simple rapid costeffective method such as DDST. Moreover, it is important to report beta lactamases production along with routine reports of antibiotic susceptibility test to help the clinician in choosing the proper antibiotics and to initiate effective infection control measures to stop their uncontrolled dissemination in healthcare settings. Further researches are needed to specify the frequency of other important $\mathrm{M} \beta \mathrm{Ls}$ genes among GNB in our locality.

\section{References}

Aktas, Z., Kayacan, C.B. 2008. Investigation of metallo- $\beta$-lactamase producing strains of Pseudomonas aeruginosa and Acinetobacter baumanni by E-test, disk synergy, and PCR. Scand. J. Infect. Dis., 40: 320-325.

Altun, S., Tufan, Z.K., Yağcı, S., Önde, U., Bulut, C., Kınıkl, S., Demiroz, A.P. 2013. Extended Spectrum Beta-lactamases, AmpC and Metallo Beta-lactamases in Emerging Multi-drug Resistant Gramnegative Bacteria in Intensive Care Units. Open. Access. Scientific. Reports, 2: 4.

Anoar, K.A., Ali, F.A. and Omer, S.A. 2014. Detection of Metallo B- lactamase enzyme in some Gram Negative Bacteria isolated from Burn Patients in Sulaimani City, Iraq. European. Sci. J., 10: 3.

Bebrone, C. 2007. Metallo-beta-lactamases (classification, activity, genetic organization, structure, zinc coordination) and their superfamily. Biochem. Pharmacol., 74: 1686-1701.

Bush, K. and Jacoby, G.A. 2010. Updated functional classifiation of betalactamases. Antimicrob. Agents Chemother., 54: 969-76.

Chakraborty, D., Basu, S. and Das, S. 2011. Study on some Gram negative multidrug resistant bacteria and their molecular characterization. Asian. J. Pharmaceut. and Clin. Res., 4(1):108-112.

Chaudhary, U., Bhaskar, H. and Sharma, M. 2008. Imipenem-EDTA disk method for rapid identification of metallo- $\beta$ lactamase producing Gram-negative bacteria. Indian J. Med. Res., 127: 406407

Collee, J.G., Miles, R.S. and Wan, B. 1996. Tests for the identification of bacteria. In: Collee JG, Fraser AG, Marmion BP, Simmons A (ed) Mackie and McCartney Practical Medical Microbiology, 14th edn. Edinburgh, Churchill Livingstone, pp 131-50.

El-Kazzaz, S.S. and Abou El-khier, N.T. 2015. 
AmpC and metallo beta-lactamases producing Gram negative bacteria in patients with hematological malignancy. African J. Microbiol. Res., 9(18): 12471254.

Ellington, M.J., Kistler, J., Livermore, D.M. and Woodford, N. 2007. Multiplex PCR for rapid detection of genes encoding acquired M $\beta$ Ls. J. Antimicrob. Chemother., 59: 321-322.

Fam, N., Diab, M., Helmi, H. and El-Dafrawy, I. 2006. Phenotypic detection of metallobeta-lactamase and extended spectrum beta-lactamases among gram negative bacterial clinical isolates. Egyptian J. Med. Microbiol., 15(4): 719-730.

Kaleem, F,. Usman, J., Hassan, A. and Khan, A. 2010. Frequency and susceptibility pattern of metallo-beta-lactamase producers in a hospital in Pakistan. $J$. Infect. Dev. Ctries., 4(12):810-13.

Karthika, R.U., Rao, R.S., Sahoo, S., Shashikala, P., Kanungo, R., Jayachandran, S., Prashanth, K. 2009. Phenotypic and genotypic assays for detecting the prevalence of metallo-betalactamases in clinical isolates of Acinetobacter baumannii from a South Indian tertiary care hospital. J. Med. Microbiol., 58: 430-435.

Kumar, M.S., Lakshmi, V. and Rajagopalan, R. 2006. Occurrence of extended spectrum $\beta$ - lactamases among Enterobacteriaceae species isolated at a tertiary care institute. Indian. J. Med. Microbiol., 24(3):208-11.

Kumar, S.H., De, A.S., Baveja, S.M., and Gore, M.A. 2012. Prevalence and risk factors of Metallobetalactamase producing Pseudomonasaeruginosa and Acinetobacter species in burns and surgical wards in a tertiary care hospital. J. Lab. Physicians, 4(1): 39-42.

Lee, J.H. and Lee, S.H. 2006. Carbapenem resistance in gram-negative pathogens: Emerging Non-metallo-carbapenemases. Res. J. Microbiol., 1: 1-22.

Lister, P.D., Wolter, D.J. and Hanson, N.D. 2009. Antibacterial Resistant Pseudomonas aeruginosa: Clinical Impact and Complex Regulation of Chromosomally Encoded Resistance Mechanisms. Clin. Microbiol. Rev., 22(4):582-610.

Mathur, P., Kapil, A., Das, B., Dhawan, B. 2002. Prevalence of extended spectrum beta lactamase producing Gram negative bacteria in a tertiary care hospital. Indian. J. Med. Res., 115:153-157.

Mishra, S..K, Acharya, J., Kattel, H.P., Koirala, J., Rijal, B.P. and Pokhrel, B.M. 2012. Metallo-beta-lactamase Producing Gramnegative Bacterial isolates. J. Nepal. Health. Res. Counc., 10(22):208-213.

Mohamed, N.M. and Raafat, D. 2011. Phenotypic and genotypicdetection of metallo-beta-lactamases in imipenemresistant Acinetobacter baumannii isolated from a tertiary hospital in Alexandria, Egypt. Res. J. Microbiol., 6(10): 750-760.

Mohammed, E.H., Fakhr, A.E., Mohammed, E.1. sayed, H.M., Al Johery, S.A.E., Abdel Ghani Hassanein, W.A.G. 2016. Spread of TEM, VIM, SHV, and CTX$\mathrm{M} \beta$-Lactamases in Imipenem-Resistant Gram-Negative Bacilli Isolated from Egyptian Hospitals. Int. J. Microbiol., 8382605.

Naveen kumar, C., Swathi, S. and Srikumar, R. 2014. Metallo-Betalatamase (MBL) detection in multidrug resistant gram negative bacilli (MDR) isolates. $J$. Innovative Res. Solution, 1 (1): 1-7.

Nordmann, P. and Poirel, L. 2002. Emerging carbapenemases in Gram negative aerobes. Clin. Microbiol. Infect., 8: 3231.

Noyal, M.J.C., Menezes, G.A., Harish, B.N., Sujatha, S. and Parija, S.C. 2009. Simple screening tests for detection of carbapenemases in clinical isolates of nonfermentative Gram-negative bacteria. Indian J. Med. Res., 129: 707-712.

Omair, M., Usman, J., Kaleem, .F, Hassa,n A., Khalid, A., Fahim, Q. 2012. Evaluation of Combined Disc Method for the Detection of Metallo- $\beta$-Lactamase Producing Gram Negative Bacilli. Malaysian J. Microbiol., 
21-25.

Pandya, J., Kamothi, M., Maheta, S., Kikani, K. and Prajapati, S. 2016. The prevalence of Metallo-beta-lactamase (MBL) in gram negative bacilli and their antimicrobial susceptibility pattern at tertiary care hospital, Surendranagar. Int. J. Res. Med., 5(3): 78-83.

Pandya, N.P., Prajapati, S.B., Mehta, S.J., Kikani, K.M. and Joshi, P.J. 2011. Evaluation of various methods for detection of metallo- $\beta$-lactamase (MBL) production in gram negative bacilli. Int. $J$. Biol. Med. Res., 2(3):775-77.

Pfaller, M.A., Jones, R.N., Doern, G.V,. Kugler, K. and the Sentry Participant Group. 1998. Bacterial pathogens isolated from patients with bloodstream infection: frequencies of occurrence and antimicrobial susceptibility patterns from the SENTRY Antimicrobial Surveillance Program (United States and Canada). Antimicrobial Agents and Chemother., 42: 1762-70.

Pitout, J., Gregson, D., Poire, 1.L. et al. 2005. Detection of pseudomonas auroginosaproducing metllo-- beta lactamases in a large centralized laboratory. J. Clin. Microbiol., 43(7): 3129-3135.

Pitout, J.D.D. 2008 Multiresistant enterobacteriaceae: new threat of an old problem. Expert Review of Anti-Infective Thrapy, 6 (5): 657-669.
Prashanth, K. and Badrinath, S. 2004. In vitro susceptibility pattern of Acinetobacter species to commonly used cephalosporins, quinolones, and aminoglycosides. Indian J. Med. Microbiol., 22 (2): 97-103.

Rasheed, J.K., Kitchel, B., Zhu, W., Anderson, K.F., Clark, N.C., Ferraro, M.J., Savard, P., Humphries, R.M., Kallen, A.J. and Limbago, B.M. 2013. New Delhi metallo$\beta \quad$ lactamase producing Enterobacteriaceae, United States. Emerg. Infect. Dis., 19: 870-878.

Shlaes, D.M., Gerding, D.N., John, J.F. et al., 1997. Society for Healthcare Epidemiology of America and Infectious Diseases Society of America joint committee on the prevention of antimicrobial resistance. Clin. Infect. Dis., 25: 584-99.

Tellis, R., Muralidharan, S. and Peter, A.I. 2013. Evaluation of three phenotypic methods for the detection of metallobetalactamase production in non fermenting gram negative bacilli. Int. J. Biomed. Advance Res., 04(05).

Wadekar, M.D., Anuradha, K. and Venkatesha, D. 2013. Phenotypic detection of ESBL and MBL in clinical isolates of Enterobacteriaceae. Int. J. Curr. Res. Academic Review, 1(3): 89-95.

\section{How to cite this article:}

Maysaa El-Sayed Zaki, Mervat Mashaly and Reham El Agamy. 2017. Phenotypic Detection and Genotypic Characterization of Metallo-Beta-Lactamases in Gram Negative Bacilli isolated from Mansoura University Hospital in Egypt. Int.J.Curr.Microbiol.App.Sci. 6(2): 1496-1505. doi: http://dx.doi.org/10.20546/ijcmas.2017.602.167 